\title{
The Effect of Brief Anxiety Interventions on Reported Anxiety and Math Test Performance
}

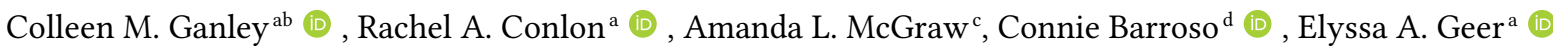 \\ [a] Department of Psychology, Florida State University, Tallahassee, FL, USA. [b] Florida Center for Research in Science, Technology, Engineering, and Mathematics, \\ Learning Systems Institute, Tallahassee, FL, USA. [c] Department of Psychology, Facksonville University, Facksonville, FL, USA. [d] Department of Educational \\ Psychology, Texas A\&M University, College Station, TX, USA.
}

Journal of Numerical Cognition, 2021, Vol. 7(1), 4-19, https://doi.org/10.5964/jnc.6065

Received: 2019-05-11 • Accepted: 2020-08-14 • Published (VoR): 2021-03-31

Corresponding Author: Colleen M. Ganley, 1107 W Call Street, Tallahassee, FL 32304, USA. E-mail: cganley@fsu.edu

Supplementary Materials: Data, Materials [see Index of Supplementary Materials]

\begin{abstract}
Research suggests that math and test anxiety have detrimental impacts on performance in math. To prevent these effects, a number of interventions have been developed, but these interventions have not been extensively tested. In the current study, we examine whether four brief anxiety interventions reduce state anxiety and/or increase math performance. We also examine whether any of the interventions weaken the relation between math or test anxiety and math performance. Participants were 300 college students varying in math and test anxiety levels. Participants were randomly assigned to one of four single-session interventions, which each took 5 minutes or less (reappraisal as challenge, reappraisal as excitement, expressive writing, and look ahead), or a no intervention control group. Results generally show that none of the interventions had an effect on reports of state anxiety or performance on a difficult math assessment, with the exception that students in the expressive writing condition reported higher levels of state anxiety. None of the interventions served to attenuate the relation between math or test anxiety and math performance. These findings were not consistent with results of previous work, and suggest that interventions may need to be more extensive in order to have an effect on state anxiety and math performance.
\end{abstract}

\section{Keywords}

math anxiety, test anxiety, interventions, math performance

Psychology researchers have long been aware of the debilitating effects of both math and test anxiety on math learning and performance, with key research in this area being conducted as early as the 1950s (Aiken, 1970; Atkinson \& Litwin, 1960; Betz, 1978; Liebert \& Morris, 1967; Sarason \& Mandler, 1952). Interventions and treatment programs designed to reduce the effects of test or math anxiety have been around for just as long, with research examining various therapeutic elements of these interventions (Hembree, 1990; Hendel \& Davis, 1978). Despite the intervention work that has been done, there is still not a large amount of evidence to support any particular intervention as the most effective. Thus, more work is needed to investigate the effectiveness of anxiety interventions that attempt to reduce anxiety and prevent the negative effects of anxiety on math performance. Current research in this area has identified some brief anxiety-reducing and performance-enhancing interventions, but in order to understand if the effects of these interventions can be generalized to a wider population, more studies testing these interventions are needed. In the current study, we test four different brief interventions that have been found to have effects on math performance by other researchers (Brooks, 2014; Jamieson, Mendes, Blackstock, \& Schmader, 2010; Mavilidi, Hoogerheide, \& Paas, 2014; Ramirez \& Beilock, 2011). We focus on 1) whether these interventions serve to decrease state anxiety and improve math 
performance and 2) whether the interventions decrease the strength of the relation between math or test anxiety and math test performance.

\section{Conceptualization of Anxiety}

Anxiety is an emotion that involves feelings of tension, worried thoughts, and physical changes (American Psychological Association [APA], 2021). It is often conceptualized using a few key distinctions. One important distinction is between trait anxiety and state anxiety. Trait anxiety refers to the general tendency to feel anxious, whereas state anxiety refers to temporary feelings of anxiety experienced in a particular situation (Hong \& Karstensson, 2002). Research shows that though these different types of anxiety are related to each other (i.e., individuals with high trait anxiety are more likely to experience more state anxiety), they represent conceptually separate constructs (Head, Engley, \& Knight, 1991; Hembree, 1990; Miller \& Bichsel, 2004).

Another important aspect of anxiety to consider is its focus. General anxiety is broad and is felt in everyday situations (APA, 2021). Test anxiety and math anxiety, on the other hand, are specific to an anxious response when faced with either testing or math situations, respectively (Ashcraft, 2002; Hembree, 1988; Richardson \& Suinn, 1972; Sarason, 1984). These two anxieties are often found to be highly correlated with one another (Hembree, 1990; Kazelskis et al., 2000), and, in the past, some researchers have argued that they may even represent the same underlying construct (Brush, 1978; Hunsley, 1987).

\section{Relation Between Anxiety and Math Performance}

Researchers consistently find that anxiety is related to math performance across a number of anxiety measures and math assessments. This relation has been found with general anxiety measures (Deffenbacher, 1980; Hembree, 1988; Williams, 1996), math anxiety measures (Barroso et al., 2021; Ganley \& Vasilyeva, 2011; Ma, 1999; Miller \& Bichsel, 2004), state anxiety measures in the context of math tests (Ganley \& Vasilyeva, 2014; Macher et al., 2013; Osborne, 2001), and test anxiety measures (Hembree, 1988; Mavilidi et al., 2014; Ramirez \& Beilock, 2011). Longitudinal work has also found a relation between math anxiety and math performance (Cargnelutti, Tomasetto, \& Passolunghi, 2017; Ma \& Xu, 2004). In general, these relations are consistent across all areas of math (Barroso et al., 2021), but some research has suggested that relations are stronger between math anxiety and math calculations or applications than between math anxiety and geometry (Vukovic, Kieffer, Bailey, \& Harari, 2013).

Thus, there is evidence for concurrent and longitudinal relations; however, the causal directions have not been fully teased apart (Ashcraft, 2002; Ma, 1999). Relations between math anxiety and math performance are often conceptualized as being bidirectional, and there is some empirical evidence to support this (Gunderson, Park, Maloney, Beilock, \& Levine, 2018; Ma \& Xu, 2004). Interestingly, the current body of research also potentially supports the idea that these bidirectional relations may occur on different time courses (Carey, Hill, Devine, \& Szücs, 2016). Specifically, research seems to support the idea that the causal effect of math performance on math anxiety may be long term, such that students reflect on negative math-related experiences and therefore become more anxious when encountering math situations in the future (Carey et al., 2016). On the other hand, there is also evidence to suggest that the causal effect of math anxiety on performance may be more situational, with state anxiety taking up available cognitive resources, such as working memory, in the moment, thus having a more immediate impact on performance (Ashcraft \& Kirk, 2001; Ashcraft \& Krause, 2007; Carey et al., 2016).

\section{Past Research on Anxiety Interventions in Math Performance Situations}

Though many studies examining the relation between anxiety and math performance use correlational data (Ashcraft, 2002; Betz, 1978; Miller \& Bichsel, 2004), there have also been experimental studies which test interventions to alleviate anxiety in a math performance context. These studies have generally found that behavioral and cognitive-behavioral interventions that reduce anxiety also improve performance (in both math and other academic areas), suggesting that these interventions affect both anxiety and performance (Hembree, 1988, 1990; Wood, 2006).

Because theory suggests the effect of anxiety on math performance may be situational (i.e., occur in the moment), we focus on interventions that are designed to alleviate anxiety immediately before testing or performance situations. 
We also focus on interventions that are brief and easy to administer to increase the potential for future use in regular classroom or testing environments. From the available anxiety interventions in the literature, we identified four interventions that met these three criteria. Importantly, past research has found that each of these interventions is effective in increasing math performance.

Two of these interventions capitalize on the multiple interpretations people can have of physiological arousal (Barrett, 2006; Blascovich, 1992) by asking participants to reappraise their anxious arousal in a more positive light, either by interpreting it as a challenge (Jamieson et al., 2010) or as excitement (Brooks, 2014). Specifically, Jamieson et al. (2010) tested whether telling participants that arousal can help performance, which put participants in a challenge frame instead of a threat frame, led to improved performance. They found that college students in the reframing condition, compared to a control condition with only basic instructions, had better performance on the math, but not the verbal, section of a practice Graduate Record Examination (GRE) test (a standardized test used for admission to graduate schools in the United States) and on the actual GRE test. In another reappraisal study, Brooks (2014) put participants in high-stress situations, including performing karaoke, giving a speech, or taking a math test, and had them reappraise their arousal as excitement. This was compared to conditions in which they either appraised their arousal as anxiety, denied any anxiety by saying they were calm, or did nothing. Across all outcomes, performance was better in the condition that included reappraisal as excitement compared to all other conditions. They also found that participants in the excitement condition reported higher excitement. They found that the effect on math performance was mediated by subjective experiences of excitement, suggesting the experience of excitement may be the mechanism for the effect.

The remaining two interventions involve the idea that anxiety has an effect on performance because it utilizes cognitive resources. Ramirez and Beilock (2011) asked participants to write about their emotions immediately before taking a math test. They suggest that if a participant writes about their worries, they can off-load these worrying thoughts and therefore reduce their cognitive load. They argue that this expressive writing then allows participants to focus their cognitive resources on the task at hand, instead of on their worries. They found, in samples of college students and ninth-grade students, that participants in the expressive writing condition had significantly higher math test scores than did participants in other conditions. They compared expressive writing to both a control condition where students sat quietly, and a comparison condition that involved a writing exercise that was not about test worries. The effect of this intervention has also been replicated in other research (Park, Ramirez, \& Beilock, 2014), but two more recent studies have failed to replicate this finding (Camerer et al., 2018; Walter, 2018). In other work based on this idea, Mavilidi et al. (2014) considered cognitive load theory and gave sixth-grade students one minute to read over a math test before taking it. They argued that this gives students an opportunity to activate the cognitive schemas needed to complete the task and reduced student anxiety so that fewer working memory resources would be used by worried thoughts, thus leaving more available to focus on the test. They found that students who looked ahead at the test had higher math performance than did students who could work on the first math problem for the first minute (to control for time) instead of looking at all of the test items.

Thus, each of these interventions has been tested separately and against different control groups to examine effects on math performance. However, their effects have not yet been examined within a single study and compared to the same control condition.

\section{Mechanisms of Performance Improvements From Interventions}

Generally, the goals of these interventions are to increase performance, which could potentially result from either a decrease in the level of anxiety itself, or a decrease in the effect this anxiety has on performance. If the first of these is true, then we should see decreases in state anxiety. If the second is true, we should see that the interventions weaken the relation between anxiety and math performance. Another way to think about this second possibility would be that the effects of the interventions are stronger for people with higher anxiety, who need the intervention most.

Past research shows mixed support for each of these possibilities. Researchers have found that allowing participants to look ahead at the questions (Mavilidi et al., 2014) and reappraising arousal as excitement (Brooks, 2014) improved performance for participants of all anxiety levels, which suggests that these interventions led to an overall decrease in anxiety. However, both of these studies actually found no intervention effects on self-reported state anxiety. With the 
expressive writing intervention, on the other hand, Ramirez and Beilock (2011) found that improvements in test scores were larger for those with high test anxiety, suggesting that the intervention was able to potentially block any effect of anxiety for those at higher levels of anxiety, a finding that was also replicated by Park et al. (2014). In this study, we will test both of these possibilities - that the interventions reduce anxiety and that they reduce the strength of the relation between anxiety and math performance - as it is possible that one or both of these are occurring with these interventions.

\section{The Present Study}

In the present study, our overall goals were to test the effects of these four interventions on both state anxiety and math performance, examine whether the relation between anxiety and performance was weaker for intervention groups, and to do this within one sample so we could assess effects when compared to the same control group. Thus, we conducted a randomized experiment to test whether each of the brief anxiety interventions (hereafter referred to as reappraisal as challenge, Jamieson et al., 2010; reappraisal as excitement, Brooks, 2014; expressive writing, Ramirez \& Beilock, 2011; and look ahead, Mavilidi et al., 2014) led to lower state anxiety and/or better math performance when compared to a control condition. Using interactions, we tested whether the relation between anxiety and performance was weaker in any of the intervention conditions than in the control condition, or, in other words, whether the effect of any of the interventions was stronger for students with higher math or test anxiety. Based on the findings of past research, we hypothesized that participants in each of the four intervention conditions would perform better on the math test than would students in the control condition. Additionally, based on past research findings, we predicted that there would be no difference in reported state anxiety for the reappraisal as excitement and look ahead conditions, but we had no hypotheses for the other two conditions. We expected that the relation between anxiety and performance would be weaker in the expressive writing condition than in the control condition, which would be consistent with the results of two previous studies, but that we would not find this for the reappraisal as excitement or look ahead conditions, for which research has not shown these interactive effects. We had no hypothesis about the relation between anxiety and performance for the reappraisal as challenge condition, as the original researchers did not examine this question.

\section{Method}

\section{Participants}

Participants were 315 college students recruited through a psychology department subject pool. Fifteen participants were removed from analyses because they took less than 10 minutes to complete the 20-item math test (an average of $<30$ seconds per item) and scored at or below chance (20\%). Thus, the final analytic sample was 300 participants. Sixty-six percent of these participants were female. Participants were, on average, 19 years and 8 months old $(S D=$ 16.96 months). Half of participants were freshman, $19.3 \%$ were sophomores, $20.7 \%$ were juniors, and $10.0 \%$ were seniors. Sixty-five percent were White, $15.7 \%$ were Hispanic/Latino, $7.7 \%$ were more than one race, $7.0 \%$ were Black or African American, $4.0 \%$ were Asian, $0.3 \%$ were another race, and $0.3 \%$ chose not to provide race or ethnicity information.

\section{Measures}

\section{Math Anxiety}

To measure math anxiety, students completed the Math Anxiety Rating Scale-Revised (Hopko, 2003). This scale is made up of 12 items assessing anxiety in specific situations involving math (e.g., Thinking about an upcoming math test one day before). Participants responded on a scale with choices 1, meaning not at all, 2 meaning a little, 3 meaning a fair amount, 4 meaning much, and 5, meaning very much. Internal consistency was high in this sample $(\alpha=.93)$.

\section{Test Anxiety}

To measure test anxiety, students completed the Cognitive Test Anxiety Scale (Cassady \& Johnson, 2002), which contains 27 items assessing anxiety in specific situations involving examination (e.g., I lose sleep over worrying about 
examinations, I am less nervous about tests than the average college student (reverse-coded)). Participants responded on a scale with choices 1, meaning not at all typical of me, 2 meaning only somewhat typical of me, 3 meaning quite typical of $m e$, and 4 , meaning very typical of me. Internal consistency was high in this sample $(\alpha=.93)$.

\section{State Anxiety}

After they completed the math test, participants answered nine items about their anxiety. Four items were from Brooks (2014; e.g., I felt anxious before the math test). These items each specifically asked participants about how they felt before the math test. Five items were adapted from Morris, Davis, and Hutchings (1981; e.g., I was worried that I might not do well on the test). For these items, we asked participants to report based on the anxiety they felt before the math test in the instructions. Participants responded on a scale with choices of 1 meaning strongly disagree, 2 meaning disagree, 3 meaning somewhat disagree, 4 meaning neither agree nor disagree, 5 meaning somewhat agree, 6 meaning agree, and 7 meaning strongly agree. Internal consistency was high in this sample $(\alpha=.90)$.

\section{Math Performance}

Students completed 20 multiple-choice items from sample tests for the quantitative reasoning section of the GRE covering number (11 items), algebra (5 items), and geometry concepts (4 items). Students were given up to 70 seconds to complete each item. Likely due to this math test measuring many diverse math concepts, the internal consistency was not high in this sample $(\alpha=.60)$. Math performance scores were calculated by assigning a 0 or 1 for correctness for each item and then calculating an average across the 20 items and multiplying by 100 . Unanswered items were assigned a 0 .

\section{Procedure}

Participants were randomly assigned to one of the four intervention conditions (reappraisal as challenge, reappraisal as excitement, expressive writing, and look ahead) or a no intervention control condition via the randomizer function within the Qualtrics survey software, which was used to administer the surveys and math test. Testing occurred individually in a laboratory on campus and all measures were completed on a desktop computer. After consent procedures, participants completed the math anxiety and test anxiety scales, then they received the experimental manipulation, and next they completed the math test. After the math test, they were asked about the anxiety they felt before the test (state anxiety). Participants answered additional filler questions when they took the math and test anxiety questions and after they took the math test. Participants were not allowed to use a calculator for the math test, but they were given scratch paper and a pencil to use.

\section{Experimental Manipulations}

\section{Reappraisal as Challenge Condition}

Participants in the reappraisal as challenge condition read the following summary of research from Jamieson et al. (2010) prior to the math test: "People think that feeling anxious while taking a standardized math test will make them do poorly on the test. However, recent research suggests that arousal doesn't hurt performance on these tests and can even help performance. People who feel anxious during a test might actually do better. This means that you shouldn't feel concerned if you do feel anxious while taking today's math test. If you find yourself feeling anxious, simply remind yourself that your arousal could be helping you do well." It took participants approximately 30-60 seconds to read this prompt.

\section{Reappraisal as Excitement Condition}

Participants in the reappraisal as excitement condition read the words "Try to get excited" on the computer screen before the math test, as was done in Brooks (2014). Participants were not required to stay on this page for a certain amount of time and were able to click "Next" whenever they chose to. It took participants approximately 2-10 seconds to read this prompt. 


\section{Expressive Writing Condition}

Based on Ramirez and Beilock (2011), before taking the math test students were asked to write about their thoughts, feelings, and emotions about the test. Students read: "Please take the next 5 minutes to write as openly as possible about your thoughts and feelings regarding the math problems you are about to perform. In your writing, I want you to really let yourself go and explore your emotions and thoughts as you are getting ready to start the math test. You might relate your current thoughts to the way you have felt during other similar situations at school or in other situations in your life. Please try to be as open as possible as you write about your thoughts at this time. Remember, there will be no identifying information on your essay. None of the experimenters can link your writing to you. Please start writing." They were then given a large textbox in which they could write. Students were unable to click "Next" to go to the next page until 5 minutes had transpired. In the original study, students were given 10 minutes; however, we only gave 5 minutes, based on pilot testing suggesting that many students got bored or confused about what they were supposed to do when they had 10 minutes to write. We coded participants' written responses and conduct some supplementary analyses with these to better understand how the content of their writing relates to key study variables.

\section{Look Ahead Condition}

Participants in the look ahead condition read "You may now take up to 2 minutes to look over the math questions that will be on this test before you take it" (from Mavilidi et al., 2014) before the math test. They were then brought to a page that contained all of the math test items. Participants were not required to stay on this page for the full two minutes, but most of them did (93.1\%). Mavilidi et al. (2014) gave students only one minute to look over the test items, but they had 10 items, therefore we used two minutes for the 20 items so that participants in our study had the same amount of time per item.

\section{Control Condition}

In the control condition, instead of seeing any of the four statements in the intervention conditions, students saw a screen that said "Click Next" and were brought to the math test. Thus, the control condition is similar to the conditions under which a student would typically take a math test.

\section{Analysis Plan}

To examine whether any of the four interventions described above led to decreased state anxiety or improved math test performance, and if any interventions decreased the relation between math or test anxiety and math performance, we conducted six hierarchical regression analyses. Three analyses included self-reported state anxiety as the outcome and three analyses included math performance as the outcome. The first analysis out of the three analyses for each outcome included math anxiety in the model, the second analysis included test anxiety in the model, and the third analysis included both math anxiety and test anxiety. For each model, we entered variables in three steps. In the first step, we included four dummy codes, one for each of the experimental conditions, with the control group as the reference group. In the second step, we included standardized scores for math anxiety, test anxiety, or both. In the third step, we included interactions between each of the experimental conditions and standardized scores for math anxiety, test anxiety, or both.

To provide additional evidence, we also conducted Bayesian analyses, where analyses were available. Bayes factors $(\mathrm{BF})$ are thus reported when applicable. Bayesian methods allow the researcher to assess the strength of the evidence for the alternative hypothesis as well as for the null hypothesis (Kass \& Raftery, 1995). We will interpret $\mathrm{BF}_{10}$ (stronger support for the alternative hypothesis) or $\mathrm{BF}_{01}$ (stronger support for the null hypothesis) values greater than 10 as strong evidence, greater than 3 as evidence, and between 1 and 3 as inconclusive (Jeffreys, 1961; Lee \& Wagenmakers, 2014). 


\section{Results}

\section{Preliminary Analyses}

We first examined whether participants took part in the interventions as intended when information was available. Similar to Brooks (2014), after the test, we asked participants whether they felt excited before the math test. Participants in the reappraisal as excitement condition were not statistically significantly more likely to say that they were excited $(M=3.13, S D=1.62)$ when compared to the mean of the four other conditions, $M=2.74, S D=1.54, t(295)=1.73, p=.08$, $d=0.25$. The Bayes factor suggests this evidence is inconclusive and therefore does not support the null hypothesis or the alternative hypothesis $\left(\mathrm{BF}_{01}=1.58\right)$. We also examined the content of the written portion for participants in the expressive writing condition to assess if they did in fact write about their thoughts in regard to the math test. We found that $95 \%$ of the sample mentioned something relating to math, suggesting that the participants generally followed the instructions provided for this intervention. Students who did not mention anything related to math were still included in the sample. Descriptive statistics and correlations are presented in Table 1.

\section{Table 1}

Descriptive Statistics and Correlations Among Math, Test, and State Anxiety and Math Performance

\begin{tabular}{|c|c|c|c|c|c|c|c|c|c|}
\hline \multirow[b]{2}{*}{ Variable } & \multicolumn{5}{|c|}{ Descriptive Statistics } & \multicolumn{4}{|c|}{ Correlations } \\
\hline & $M$ & $S D$ & Scale & Skew & Kurtosis & $\begin{array}{c}\text { Math } \\
\text { Anxiety }\end{array}$ & $\begin{array}{c}\text { Test } \\
\text { Anxiety }\end{array}$ & State Anxiety & Math Score \\
\hline Math Anxiety & 2.31 & 0.80 & $1-5$ & 0.71 & -0.10 & - & & & \\
\hline Test Anxiety & 2.31 & 0.53 & $1-4$ & 0.31 & -0.22 & $.55^{* * *}$ & - & & \\
\hline State Anxiety & 3.98 & 1.31 & $1-7$ & 0.12 & -0.64 & $.51^{* * *}$ & $.58^{* * *}$ & - & \\
\hline Math Score & 33.17 & 13.91 & $0-100$ & 0.77 & 0.79 & $-.28^{* * *}$ & $-.27^{* * *}$ & $-.24^{* * *}$ & - \\
\hline
\end{tabular}

There were no significant issues with skew or kurtosis (Hair, Anderson, Babin, \& Black, 2010; Tabachnick \& Fidell, 2013). The means for math, test, and state anxiety were all at or just below the midpoint of the scales, suggesting this is not a particularly math- or test-anxious sample, and that participants did not experience high levels of anxiety before the math test (state anxiety). These means are similar to those found in other studies using these measures (e.g., Cassady \& Finch, 2015; Ganley \& Vasilyeva, 2014; Hart \& Ganley, 2019). Performance on the math test was low, but there was sufficient variability (see Figure S1 in the Supplementary Materials for a histogram of scores). Correlations show that math anxiety and test anxiety are strongly positively correlated with each other and with state anxiety, and they all show significant, small-to-moderate, negative correlations with math test performance.

Table 2 displays means and standard deviations for math anxiety, test anxiety, state anxiety, and math test performance for participants in each of the five conditions. To test if there were differences by condition in initial levels of math and test anxiety, we conducted two regression analyses using the four dummy codes for condition as predictors of inital levels of either math anxiety or test anxiety. The overall models were not significant, math anxiety: $F(4,295)=2.12, R^{2}$ $=.03, p=.08$, test anxiety: $F(4,295)=1.98, R^{2}=.03, p=.10$, but regression coefficients showed that participants in the reappraisal as challenge condition had higher math and test anxiety, on average, than did participants in the control condition (math anxiety: $b=0.39, S E=0.15, p=.008$; test anxiety: $b=0.27, S E=0.10, p=.006$; see Table S1 in the Supplementary Materials). In our analyses, these initial levels of math and/or test anxiety are included as covariates, which statistically accounts for these differences. 
Table 2

Mean Math, Test, and State Anxiety and Math Performance by Condition

\begin{tabular}{|c|c|c|c|c|c|c|c|c|c|}
\hline \multirow[b]{2}{*}{ Condition } & \multirow[b]{2}{*}{$n$} & \multicolumn{2}{|c|}{ Math Anxiety } & \multicolumn{2}{|c|}{ Test Anxiety } & \multicolumn{2}{|c|}{ State Anxiety } & \multicolumn{2}{|c|}{ Math Score } \\
\hline & & $M$ & $S D$ & $M$ & $S D$ & $M$ & $S D$ & $M$ & $S D$ \\
\hline Reappraisal as challenge (Jamieson et al., 2010) & 59 & 2.51 & 0.83 & 2.44 & 0.54 & 4.14 & 1.26 & 33.90 & 14.56 \\
\hline Reappraisal as excitement (Brooks, 2014) & 63 & 2.32 & 0.83 & 2.31 & 0.48 & 3.86 & 1.29 & 32.38 & 13.16 \\
\hline Expressive writing (Ramirez \& Beilock, 2011) & 63 & 2.21 & 0.72 & 2.28 & 0.48 & 4.28 & 1.30 & 32.14 & 12.00 \\
\hline Look ahead (Mavilidi et al., 2014) & 58 & 2.37 & 0.81 & 2.33 & 0.58 & 3.88 & 1.38 & 33.10 & 14.65 \\
\hline Control & 57 & 2.12 & 0.76 & 2.17 & 0.53 & 3.71 & 1.26 & 34.47 & 15.49 \\
\hline
\end{tabular}

\section{Main Effects of Condition, Math Anxiety, and Test Anxiety}

Results from the hierarchical regression analyses are displayed in Table 3 for state anxiety and Table 4 for math test performance. To test the main effects of condition with no other variables in the model, we included the four dummy codes for the experimental conditions in the first step. When predicting state anxiety, we found that only the expressive writing condition was statistically significantly different from the control condition $\left(\beta=0.18, p=.016, \mathrm{sr}^{2}\right.$ $=.02$ ). Bayesian results also suggested evidence in favor of a difference between these conditions, but it was in the inconclusive range $\left(\mathrm{BF}_{10}=2.69\right)$. The direction of the regression coefficient indicates that participants in the expressive writing condition actually reported higher levels of state anxiety $(M=4.28, S D=1.29)$ than did participants in the control condition $(M=3.71, S D=1.26)$, which is the opposite of what we would expect if the intervention decreased anxiety as intended. All other conditions were not statistically significantly different from the control condition in state anxiety $(p s \geq .09)$ and Bayesian analyses show that the difference between the reappraisal as a challenge condition and the control condition was inconclusive $\left(\mathrm{BF}_{10}=1.03\right)$, but evidence was in favor of the null hypothesis for the reappraisal as excitement $\left(\mathrm{BF}_{01}=4.50\right)$ and look ahead conditions $\left(\mathrm{BF}_{01}=3.79\right)$.

Table 3

Standardized Regression Coefficients for Regression Analyses Predicting State Anxiety

\begin{tabular}{|c|c|c|c|c|c|c|c|c|c|}
\hline \multirow[b]{2}{*}{ Variable } & \multicolumn{3}{|c|}{ Math Anxiety Only } & \multicolumn{3}{|c|}{ Test Anxiety Only } & \multicolumn{3}{|c|}{ Both Math and Test Anxiety } \\
\hline & Model 1 & Model 2 & Model 3 & Model 1 & Model 2 & Model 3 & Model 1 & Model 2 & Model 3 \\
\hline Challenge & 0.13 & 0.03 & 0.03 & 0.13 & 0.01 & 0.02 & 0.13 & -0.01 & -0.01 \\
\hline Excitement & 0.05 & -0.01 & -0.01 & 0.05 & -0.02 & -0.01 & 0.05 & -0.03 & -0.04 \\
\hline Writing & $0.18^{*}$ & $0.15^{*}$ & $0.14^{*}$ & $0.18^{*}$ & $0.13^{*}$ & $0.13^{*}$ & $0.18^{*}$ & $0.13^{*}$ & $0.12^{*}$ \\
\hline Look Ahead & 0.05 & -0.01 & -0.02 & 0.05 & -0.02 & -0.02 & 0.05 & -0.03 & -0.04 \\
\hline Math Anxiety & & $0.51^{* * *}$ & $0.60^{* * *}$ & & & & & $0.28^{* * *}$ & $0.41^{* *}$ \\
\hline Test Anxiety & & & & & $0.58^{* * *}$ & $0.57^{* * *}$ & & $0.43^{* * *}$ & $0.39^{* *}$ \\
\hline Challenge x Math Anxiety & & & -0.08 & & & & & & -0.08 \\
\hline Excitement x Math Anxiety & & & -0.05 & & & & & & -0.05 \\
\hline Writing x Math Anxiety & & & -0.03 & & & & & & -0.06 \\
\hline Look Ahead x Math Anxiety & & & -0.02 & & & & & & -0.09 \\
\hline Challenge $\mathrm{x}$ Test Anxiety & & & & & & -0.03 & & & -0.01 \\
\hline Excitement x Test Anxiety & & & & & & 0.01 & & & 0.01 \\
\hline Writing x Test Anxiety & & & & & & 0.02 & & & 0.03 \\
\hline Look Ahead x Test Anxiety & & & & & & 0.03 & & & 0.05 \\
\hline$\Delta R^{2}$ & & $.26^{* * *}$ & .003 & & $.33^{* * *}$ & .002 & & $.38^{* * *}$ & .005 \\
\hline$R^{2}$ & .03 & $.28^{* * *}$ & $.29^{* *}$ & .03 & $.35^{* * *}$ & $.35^{* * *}$ & .03 & $.41^{* * *}$ & $.41^{* * *}$ \\
\hline
\end{tabular}


For math performance, we did not find statistically significant differences between any of the anxiety interventions and the control condition ( $p s \geq .36$ ). Bayes factors all showed support for the null hypothesis $\left(\mathrm{BF}_{01} \mathrm{~s} \geq 3.49\right)$. The experimental design overall only accounted for a nonsignificant $3 \%$ of the variance in state anxiety and $0.4 \%$ of the variance in math performance.

Table 4

Standardized Regression Coefficients for Regression Analyses Predicting Math Test Scores

\begin{tabular}{|c|c|c|c|c|c|c|c|c|c|}
\hline \multirow[b]{2}{*}{ Variable } & \multicolumn{3}{|c|}{ Math Anxiety Only } & \multicolumn{3}{|c|}{ Test Anxiety Only } & \multicolumn{3}{|c|}{ Both Math and Test Anxiety } \\
\hline & Model 1 & Model 2 & Model 3 & Model 1 & Model 2 & Model 3 & Model 1 & Model 2 & Model 3 \\
\hline Challenge & -0.02 & 0.04 & 0.06 & -0.02 & 0.04 & 0.06 & -0.02 & 0.06 & 0.08 \\
\hline Excitement & -0.06 & -0.03 & -0.03 & -0.06 & -0.03 & -0.02 & -0.06 & -0.02 & -0.01 \\
\hline Writing & -0.07 & -0.06 & -0.05 & -0.07 & -0.05 & -0.04 & -0.07 & -0.05 & -0.03 \\
\hline Look Ahead & -0.04 & -0.00 & -0.01 & -0.04 & -0.01 & 0.00 & -0.04 & 0.00 & 0.01 \\
\hline Math Anxiety & & $-0.28^{* * *}$ & $-0.31^{*}$ & & & & & $-0.19^{* *}$ & -0.17 \\
\hline Test Anxiety & & & & & $-0.27^{* * *}$ & $-0.37^{* *}$ & & $-0.17^{*}$ & $-0.30^{*}$ \\
\hline Challenge x Math Anxiety & & & -0.05 & & & & & & -0.07 \\
\hline Excitement x Math Anxiety & & & -0.00 & & & & & & -0.02 \\
\hline Writing x Math Anxiety & & & 0.04 & & & & & & 0.02 \\
\hline Look Ahead x Math Anxiety & & & 0.08 & & & & & & -0.00 \\
\hline Challenge $\mathrm{x}$ Test Anxiety & & & & & & 0.00 & & & 0.05 \\
\hline Excitement x Test Anxiety & & & & & & -0.01 & & & 0.01 \\
\hline Writing x Test Anxiety & & & & & & 0.05 & & & 0.04 \\
\hline Look Ahead x Test Anxiety & & & & & & 0.16 & & & 0.18 \\
\hline$\Delta R^{2}$ & & $.08^{* * *}$ & .01 & & $.07^{* * *}$ & .02 & & $.10^{* * *}$ & .02 \\
\hline$R^{2}$ & .004 & $.08^{* * *}$ & $.09^{* * *}$ & .004 & $.08^{* * *}$ & $.10^{* * *}$ & .004 & $.10^{* * *}$ & $.13^{* * *}$ \\
\hline
\end{tabular}

In the second step, we added either math anxiety or test anxiety, or both, as additional predictors (Model $2 \mathrm{~s}$ in Table 3 and Table 4). Across all models, both variables were statistically significant predictors of state anxiety and math performance. In addition, the pattern of effects found for condition remained, with the only significant coefficient in each model being the one for the expressive writing condition on state anxiety $(0.13 \leq \beta \mathrm{s} \leq 0.15 ; .018 \leq p \mathrm{~s} \leq .032 ; .01 \leq$ $\left.\mathrm{sr}^{2} \mathrm{~s} \leq .02\right)$. For state anxiety, adding both math and test anxiety significantly increased the amount of variance explained by $38.5 \%(p<.001)$. For math performance, adding both math and test anxiety significantly increased the amount of variance explained by $9.7 \%(p<.001)$.

\section{Interactions Between Condition and Math and Test Anxiety}

In the third step of analyses, we included interactions between either math anxiety and each experimental condition or test anxiety and each condition, or both (Model 3s in Table 3 and Table 4). Across analyses, we found no evidence for any statistically significant interactive effects on either state anxiety or math performance (see Figure 1). The significant main effects held. The only significant coefficient for condition was the effect of the expressive writing condition on state anxiety $\left(0.12 \leq \beta \mathrm{s} \leq 0.15 ; .029 \leq p \mathrm{~s} \leq .050, .01 \leq \mathrm{sr}^{2} \mathrm{~s} \leq .02\right)$. Math anxiety and test anxiety were statistically significant predictors across models, with the exception of math anxiety no longer being a significant predictor of math performance when both math and test anxiety and their interactions with the conditions were included in the model $(\beta=-0.17, p=.28)$. For both outcomes, adding the interaction terms did not lead to a significant increase in variance explained in any model $\left(.002 \leq \Delta R^{2} \leq .02\right)$. 
Figure 1

Relations of Math Anxiety and Test Anxiety With State Anxiety and Math Test Scores Across Experimental Conditions

A

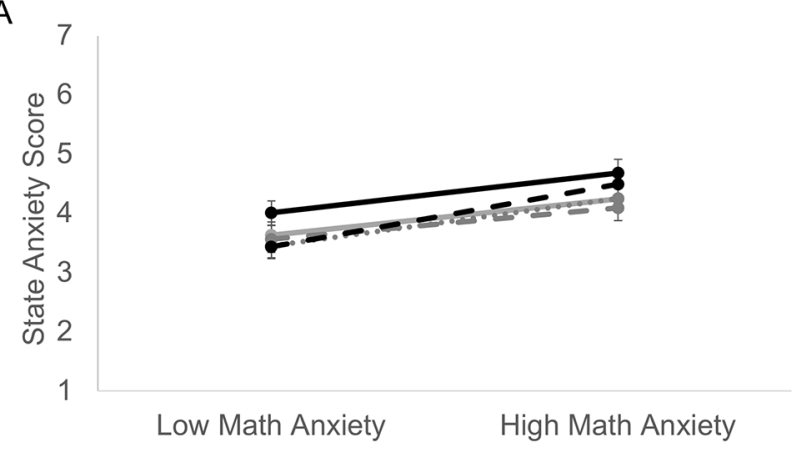

C

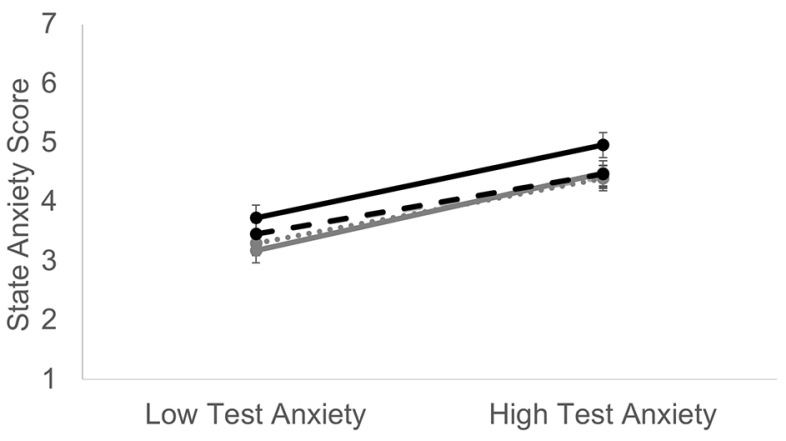

B

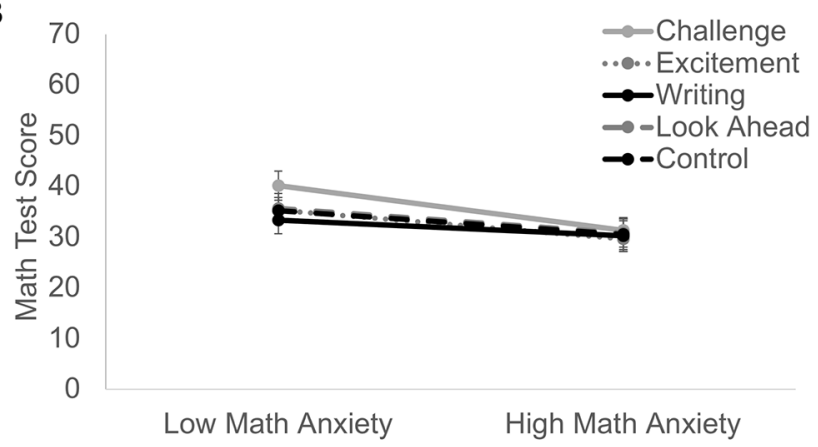

D

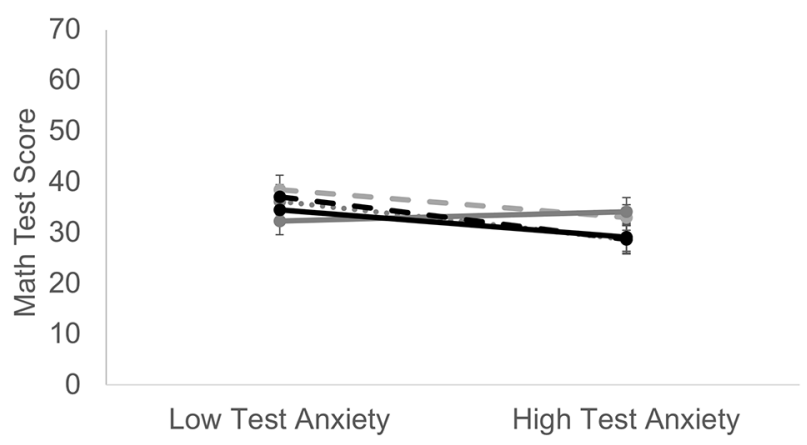

Note. The relation of math anxiety with (A) state anxiety score and (B) math test performance and the relation of test anxiety with (C) state anxiety score and (D) math test performance across experimental conditions. Low anxiety is modelled at $1 S D$ below the mean and high anxiety is modelled at $1 S D$ above the mean. Error bars represent standard errors. Challenge $=$ reappraisal as challenge; Excitement $=$ reappraisal as excitement; Writing $=$ expressive writing.

Based on research by Vukovic et al. (2013) suggesting that math anxiety may be less related to geometry performance, we also conducted these same hierarchical regression analyses separately for items that assessed number concepts (11 items), algebra (5 items), or geometry (4 items). The zero-order correlations showed significant negative correlations between math and test anxiety with all three math content areas $(-.26 \leq r s \leq-.12$; Table S2 in the Supplementary Materials). Means and standard deviations for performance on each subscale in each of the five conditions are presented in Table S3 in the Supplementary Materials. Results for the hierarchical regression analyses were generally consistent with those for the total score (Tables S4-S6 in the Supplementary Materials). The only differences were that math and test anxiety were less consistent predictors of performance when they were included together or when interactions were included. There was also one case, for geometry performance and the model with both math and test anxiety, where the interaction between the look ahead condition and test anxiety was statistically significant, suggesting that the relation between test anxiety and geometry performance was weaker for those in the look ahead condition compared to those in the control condition.

\section{Supplementary Analyses for the Expressive Writing Intervention}

The content of the written responses for participants in the expressive writing condition $(n=63)$ was also examined. Two independent coders assessed if written responses included mention of one or more of the following: 1) test or math anxiety, 2) specific but unrelated anxiety, 3) unspecified anxiety, 4) hating math, 5) other negative emotions, 6) self-confidence regarding the test, or 7) other positive emotions. Raters agreed on $87 \%$ of the responses. Any outstanding 
disagreements were discussed and resolved by the raters. Because only one participant reported unspecified anxiety, we did not analyze this variable in the following analyses.

Participants reported a range of negative emotions, with 58\% reporting test or math anxiety, $32 \%$ reporting specific but unrelated anxiety, $16 \%$ reporting hating math, and $26 \%$ reporting other negative emotions. Participants also reported a number of positive emotions, with $19 \%$ reporting self-confidence regarding the test and $50 \%$ reporting other positive emotions.

A series of one-way ANOVAs was used to explore if mentioning anything that fits into the categories above was related to reported state anxiety or to math performance. A significant relation was found for mentions of test or math anxiety $\left(p<.001 ; \mathrm{BF}_{10}=72.37\right)$ and hating math $\left(p=.028 ; \mathrm{BF}_{10}=2.36\right)$ such that those whose written response contained mentions of test anxiety or math anxiety, or hating math, reported higher levels of state anxiety, though the result for hating math is inconclusive based on Bayesian analyses. In addition, those who wrote about self-confidence regarding the test $\left(p=.031 ; \mathrm{BF}_{10}=1.87\right)$, or included other positive comments $\left(p=.008 ; \mathrm{BF}_{10}=11.56\right)$ reported lower levels of state anxiety, though the Bayesian results are inconclusive for self-confidence. There was no significant relation between reported state anxiety levels and writing about anxiety specifically unrelated to the test $\left(p=.26 ; \mathrm{BF}_{01}=2.16\right)$ or other negative comments $\left(p=.42, \mathrm{BF}_{01}=1.51\right)$, and both of these had inconclusive Bayesian results. In addition, there were no significant relations between any of the coded categories of writing content and math test performance ( $p s>.13 ; 2.82<$ $\mathrm{BF}_{01} \mathrm{~s}<3.31$ ), which were generally just around the cutoff between inconclusive and support for the null hypothesis in the Bayesian analyses.

\section{Discussion}

We have long known about the detrimental impacts of anxiety on math performance. However, there is less work investigating potential interventions for alleviating this anxiety and improving math performance. In this study, we examined the effectiveness of four recently-developed brief anxiety interventions used with math tests, and whether their effects interacted with math and/or test anxiety. We found only one intervention effect: the expressive writing intervention increased self-reported state anxiety, an effect in the opposite direction of what would be expected if the intervention led to reductions in anxiety. There were no effects of any of the interventions on math performance. We also did not find that the condition a participant was assigned to moderated the relation between math or test anxiety and state anxiety or math performance. We did find overall unique relations for math and test anxiety with both state anxiety and math performance, even when they were included in regression analyses simultaneously (with one exception).

Despite empirical evidence from at least one published study showing improved math performance for each of the interventions we tested, we did not find evidence of this effect for any of the interventions. Although there were fewer studies that had examined intervention effects on state anxiety, the two that had done so reported finding no effects on state anxiety, which our results corroborated (Brooks, 2014; Mavilidi et al., 2014). We did find one effect on state anxiety, but it was in the opposite direction of what would be expected. Specifically, participants in the expressive writing condition actually reported higher state anxiety than those in the control condition. We think that this may have been an activation effect, as participants were asked to specifically write about their emotions before the test and this may have made anxiety more salient to them (Schmader \& Johns, 2003; Wegner, Schneider, Carter, \& White, 1987). This idea is supported by our supplemental analyses for the expressive writing condition, where we found that students who mentioned math or test anxiety during expressive writing at the beginning of the test were more likely to report that they felt anxious at the beginning of the test. This finding runs counter to the original intention of the intervention, which was based on the idea that writing down worries would allow participants to off-load their worry and focus their cognitive resources on the math test. Interestingly, we saw no difference between this condition and the control condition on math test performance, which suggests that any increase in reported anxiety did not cause performance differences, and also that it is unlikely that an off-loading of anxiety related to performance occurred.

There are a number of potential reasons why we found mainly null effects for our interventions. First, there may have been variablility in how participants interpreted the instructions, especially for the reappraisal as excitement 
condition, which could have been confusing to some participants. Second, each intervention was deliberately selected for feasible application and brevity when used within regular testing and classroom situations, and as such each intervention ranged from two seconds to five minutes in length and was administered in a single session. However, the short duration of the session, and the lack of repeated sessions, may have made it less likely for the interventions to have an impact on reported state anxiety or math performance. There was also variability across the conditions in the length of the intervention, so those that were shorter even among these may have been at a comparative disadvantage. Third, it is possible that our participants did not have high enough anxiety for our interventions to have an impact. Some researchers used high-pressure inducing procedures to increase anxiety within average anxiety samples (Mavilidi et al., 2014; Ramirez \& Beilock, 2011), but in our case the state anxiety ratings in our sample were not particularly high, on average, and we did not purposely induce anxiety. However, our results showed that the effects of the interventions were not different for those with higher levels of math or test anxiety, suggesting this sampling issue is unlikely to explain our results. Regardless, future work on these interventions could examine samples selected specifically for higher levels of math or test anxiety to help rule this out. Fourth, interventions targeting math anxiety may cause changes in other emotions often felt about math, such as anger or frustration (e.g., Pekrun, Frenzel, Goetz, \& Perry, 2007); however, other emotions were not measured in the present study. Lastly, each of the interventions focused on cognitive aspects of anxiety, and not specifically on the physiological component of anxiety (Liebert \& Morris, 1967). The two reappraisal conditions do focus on cognitive reappraisal of physiological aspects of anxiety, but they do not directly target changes in the physiological component of anxiety (such as breathing exercises; e.g., Brunyé et al., 2013).

The finding of overall relations between math and test anxiety and math performance fits with much past research examining this association (Barroso et al., 2021; Hembree, 1988, 1990; Ma, 1999). The lack of significant interactions between experimental condition and math or test anxiety suggests that the relation between math and test anxiety with math performance was similar across experimental groups. Thus, no intervention was able to mitigate the negative relation between math or test anxiety and performance.

\section{Limitations}

It is important to note a number of limitations to this study, chief among them that this was not a direct replication of any of the original studies. Diverging from the exact methods of each study was necessary in order to include all of the interventions in one study. We had to use the same control group for all of the interventions and therefore could not use the exact control/comparison groups from each of the original studies. In addition, some small changes were made for logistical reasons, as noted in the Method section. For example, instructions were provided on screen, which may not have had the same effect as being read aloud by a person, as they had been in Jamieson et al. (2010) and Mavilidi et al. (2014). In addition, the participants in this study were college students from one university in the United States, and thus these interventions may have different effects in other contexts, such as for children or in other cultures, which should be explored in future research.

In regard to the state anxiety scale, after the test we asked participants to retrospectively report on the anxiety they felt before the test. This could have given us different results than if we had asked them to report their anxiety in the moment before the test or had we asked about the anxiety they experienced during or after the test. It is also possible that some participants misinterpreted what we meant by "before the test" and reported their anxiety at the beginning of the study session instead of immediately prior to the test itself. Thus, it is possible they reported on anxiety felt prior to being exposed to the experimental manipulation. In addition, because this report occurred after the test, participants may have been more relaxed and their report may not have been an accurate reflection of their prior anxiety, though some of our recent work suggests this is unlikely (Conlon et al., 2021).

Our math test also had some issues with reliability. There is some evidence for its validity, however, as it is correlated with math anxiety at a similar strength $(r=-.28)$ as found in meta-analyses (Barroso et al., 2021: -.28; Hembree, 1990: -.34; Ma, 1999: -.27). Regardless, this low reliability could have attenuated any effects of the interventions. The math test was also quite challenging $(M=33.17 \%)$, which could have decreased effort or motivation of participants. It may also have had an impact on the effectiveness of the interventions, especially the look ahead condition (Mavilidi et al., 2014), 
as seeing the difficult items ahead of time may not have alleviated anxiety, but kept it stable or even increased it for some participants.

\section{Conclusion}

Although past researchers found that each of these four interventions increased math performance, we did not find evidence for better math performance or lower state anxiety compared to a control group in the present study. Thus, we did not obtain the original performance effects for any of these interventions. We also did not find that they decreased state anxiety, which fits with past work on the two interventions that have tested this effect. These results suggest we may need to focus future research on other strategies for reducing the effects of math anxiety. These interventions were purposely selected because they were brief and easy to administer without large disruption to regular testing situations, giving them ecological validity. This, however, may not be enough of a dose to cause meaningful changes in state anxiety and math test performance. Perhaps these same strategies must be longer in duration and/or given across multiple sessions to have their intended effects. Alternatively, perhaps different interventions that borrow from current practice in Clinical Psychology for general anxiety would be more effective (e.g. van Ingen, Freiheit, \& Vye, 2009). These interventions can work to decrease trait-level math and/or test anxiety over the long term, which might then lead to lower state anxiety in math or test situations, and subsequently better performance.

Funding: The authors have no funding to report.

Acknowledgments: The authors have no support to report.

Competing Interests: The authors have declared that no competing interests exist.

Data Availability: For this article, a dataset is freely available (Ganley, Conlon, McGraw, Barroso, \& Geer, 2020).

\section{Supplementary Materials}

The Supplementary Materials contain the data, codebook, data analysis code, instruments and Supplementary Figure S1 and Tables S1 - S6 for this study (for access see Index of Supplementary Materials below).

\section{Index of Supplementary Materials}

Ganley, C. M., Conlon, R. A., McGraw, A. L., Barroso, C., \& Geer, E. A. (2020). Supplementary materials to "The effect of brief anxiety interventions on reported anxiety and math test performance” [Data, codebook, code, and instruments]. OSF. https://osf.io/npzt7

Ganley, C. M., Conlon, R. A., McGraw, A. L., Barroso, C., \& Geer, E. A. (2021). Supplementary materials to "The effect of brief anxiety interventions on reported anxiety and math test performance" [Supplementary figures and tables]. PsychOpen GOLD.

https://doi.org/10.23668/psycharchives.4640

\section{References}

Aiken, L. R., Jr. (1970). Attitudes toward mathematics. Review of Educational Research, 40(4), 551-596.

https://doi.org/10.3102/00346543040004551

American Psychological Association. (2021). Anxiety. Retrieved from https://www.apa.org/topics/anxiety

Ashcraft, M. H. (2002). Math anxiety: Personal, educational, and cognitive consequences. Current Directions in Psychological Science, 11(5), 181-185. https://doi.org/10.1111/1467-8721.00196

Ashcraft, M. H., \& Kirk, E. P. (2001). The relationships among working memory, math anxiety, and performance. fournal of Experimental Psychology: General, 130(2), 224-237. https://doi.org/10.1037/0096-3445.130.2.224

Ashcraft, M. H., \& Krause, J. A. (2007). Working memory, math performance, and math anxiety. Psychonomic Bulletin \& Review, 14(2), 243-248. https://doi.org/10.3758/BF03194059 
Atkinson, J. W., \& Litwin, G. H. (1960). Achievement motive and test anxiety conceived as motive to approach success and motive to avoid failure. Journal of Abnormal and Social Psychology, 60(1), 52-63. https://doi.org/10.1037/h0041119

Barrett, L. F. (2006). Solving the emotion paradox: Categorization and the experience of emotion. Personality and Social Psychology Review, 10(1), 20-46. https://doi.org/10.1207/s15327957pspr1001_2

Barroso, C., Ganley, C. M., McGraw, A. L., Geer, E. A., Hart, S. A., \& Daucourt, M. C. (2021). A meta-analysis of the relation between math anxiety and math achievement. Psychological Bulletin, 147(2), 134-168. https://doi.org/10.1037/bul0000307

Betz, N. E. (1978). Prevalence, distribution, and correlates of math anxiety in college students. fournal of Counseling Psychology, 25(5), 441-448. https://doi.org/10.1037/0022-0167.25.5.441

Blascovich, J. (1992). A biopsychsocial approach to arousal regulation. fournal of Social and Clinical Psychology, 11, $213-237$. https://doi.org/10.1521/jscp.1992.11.3.213

Brooks, A. W. (2014). Get excited: Reappraising pre-performance anxiety as excitement. fournal of Experimental Psychology: General, 143(3), 1144-1158. https://doi.org/10.1037/a0035325

Brunyé, T. T., Mahoney, C. R., Giles, G. E., Rapp, D. N., Taylor, H. A., \& Kanarek, R. B. (2013). Learning to relax: Evaluating four brief interventions for overcoming the negative emotions accompanying math anxiety. Learning and Individual Differences, $27,1-7$. https://doi.org/10.1016/j.lindif.2013.06.008

Brush, L. R. (1978). A validation study of the Mathematics Anxiety Rating Scale (MARS). Educational and Psychological Measurement, 38, 485-499. https://doi.org/10.1177/001316447803800236

Camerer, C. F., Dreber, A., Holzmeister, F., Ho, T.-H., Huber, J., Johannesson, M., . . Wu, H. (2018). Evaluating the replicability of social science experiments in Nature and Science between 2010 and 2015. Nature Human Behaviour, 2, 637-644. https://doi.org/10.1038/s41562-018-0399-Z

Carey, E., Hill, F., Devine, A., \& Szücs, D. (2016). The chicken or the egg? The direction of the relationship between mathematics anxiety and mathematics performance. Frontiers in Psychology, 6, Article 1987. https://doi.org/10.3389/fpsyg.2015.01987

Cargnelutti, E., Tomasetto, C., \& Passolunghi, M. C. (2017). How is anxiety related to math performance in young students? A longitudinal study of grade 2 to grade 3 children. Cognition and Emotion, 31(4), 755-764. https://doi.org/10.1080/02699931.2016.1147421

Cassady, J. C., \& Finch, W. H. (2015). Using factor mixture modeling to identify dimensions of cognitive test anxiety. Learning and Individual Differences, 41, 14-20. https://doi.org/10.1016/j.lindif.2015.06.002

Cassady, J. C., \& Johnson, R. E. (2002). Cognitive test anxiety and academic performance. Contemporary Educational Psychology, 27(2), 270-295. https://doi.org/10.1006/ceps.2001.1094

Conlon, R. A., Hicks, A., Barroso, C., \& Ganley, C. M. (2021). The effect of the timing of math anxiety measurement on math outcomes. Learning and Individual Differences, 86, Article 101962. https://doi.org/10.1016/j.lindif.2020.101962

Deffenbacher, J. L. (1980). Worry and emotionality in test anxiety. In I. G. Sarason (Ed.), Test anxiety: Theory, research, and applications (pp. 111-128). Hillsdale, NJ, USA: Erlbaum.

Ganley, C. M., \& Vasilyeva, M. (2011). Sex differences in the relation between math performance, spatial skills, and attitudes. Fournal of Applied Developmental Psychology, 32(4), 235-242. https://doi.org/10.1016/j.appdev.2011.04.001

Ganley, C. M., \& Vasilyeva, M. (2014). The role of anxiety and working memory in gender differences in mathematics. fournal of Educational Psychology, 106(1), 105-120. https://doi.org/10.1037/a0034099

Gunderson, E. A., Park, D., Maloney, E. A., Beilock, S. L., \& Levine, S. C. (2018). Reciprocal relations among motivational frameworks, math anxiety, and math achievement in early elementary school. Journal of Cognition and Development, 19(1), 21-46. https://doi.org/10.1080/15248372.2017.1421538

Hair, J. F., Anderson, R. E., Babin, B. J., \& Black, W. C. (2010). Multivariate data analysis: A global perspective (Vol. 7). Upper Saddle River, NJ, USA: Pearson.

Hart, S. A., \& Ganley, C. M. (2019). The nature of math anxiety in adults: Prevalence and correlates. Fournal of Numerical Cognition, 5(2), 122-139. https://doi.org/10.5964/jnc.v5i2.195

Head, L. Q., Engley, E., \& Knight, C. B. (1991). The effects of trait anxiety on state anxiety and perception of test difficulty for undergraduates administered high and low difficulty tests. fournal of Instructional Psychology, 18(1), 65-68.

Hembree, R. (1988). Correlates, causes, effects, and treatment of test anxiety. Review of Educational Research, 58(1), 47-77. https://doi.org/10.3102/00346543058001047 
Hembree, R. (1990). The nature, effects, and relief of mathematics anxiety. fournal for Research in Mathematics Education, 21(1), 33-46. https://doi.org/10.2307/749455

Hendel, D. D., \& Davis, S. O. (1978). Effectiveness of an intervention strategy for reducing mathematics anxiety. Fournal of Counseling Psychology, 25(5), 429-434. https://doi.org/10.1037/0022-0167.25.5.429

Hong, E., \& Karstensson, L. (2002). Antecedents of state test anxiety. Contemporary Educational Psychology, 27(2), 348-367. https://doi.org/10.1006/ceps.2001.1095

Hopko, D. R. (2003). Confirmatory factor analysis of the Math Anxiety Rating Scale-Revised. Educational and Psychological Measurement, 63(2), 336-351. https://doi.org/10.1177/0013164402251041

Hunsley, J. (1987). Cognitive processes in mathematics anxiety and test anxiety: The role of appraisals, internal dialogue, and attributions. Fournal of Educational Psychology, 79(4), 388-392. https://doi.org/10.1037/0022-0663.79.4.388

Jamieson, J. P., Mendes, W. B., Blackstock, E., \& Schmader, T. (2010). Turning the knots in your stomach into bows: Reappraising arousal improves performance on the GRE. Journal of Experimental Social Psychology, 46(1), 208-212.

https://doi.org/10.1016/j.jesp.2009.08.015

Jeffreys, H. (1961). Theory of probability (3rd ed.). Oxford, United Kingdom: Oxford University Press.

Kass, R. E., \& Raftery, A. E. (1995). Bayes factors. fournal of the American Statistical Association, 90(430), 773-795. https://doi.org/10.1080/01621459.1995.10476572

Kazelskis, R., Reeves, C., Kersh, M. E., Bailey, G., Cole, K., Larmon, M., . . Holliday, D. C. (2000). Mathematics anxiety and test anxiety: Separate constructs? Journal of Experimental Education, 68(2), 137-146. https://doi.org/10.1080/00220970009598499

Lee, M. D., \& Wagenmakers, E. J. (2014). Bayesian cognitive modeling: A practical course. New York, NY, USA, Cambridge University Press. https://doi.org/10.1017/CBO9781139087759

Liebert, R. M., \& Morris, L. W. (1967). Cognitive and emotional components of test anxiety: A distinction and some initial data. Psychological Reports, 20(3), 975-978. https://doi.org/10.2466/pr0.1967.20.3.975

Ma, X. (1999). A meta-analysis of the relationship between anxiety toward mathematics and achievement in mathematics. fournal for Research in Mathematics Education, 30(5), 520-540. https://doi.org/10.2307/749772

Ma, X., \& Xu, J. (2004). The causal ordering of mathematics anxiety and mathematics achievement: A longitudinal panel analysis. Fournal of Adolescence, 27(2), 165-179. https://doi.org/10.1016/j.adolescence.2003.11.003

Macher, D., Paechter, M., Papousek, I., Ruggeri, K., Freudenthaler, H. H., \& Arendasy, M. (2013). Statistics anxiety, state anxiety during an examination, and academic achievement. The British fournal of Educational Psychology, 83(4), 535-549. https://doi.org/10.1111/j.2044-8279.2012.02081.x

Mavilidi, M.-F., Hoogerheide, V., \& Paas, F. A. (2014). Quick and easy strategy to reduce test anxiety and enhance test performance. Applied Cognitive Psychology, 28(5), 720-726. https://doi.org/10.1002/acp.3058

Miller, H., \& Bichsel, J. (2004). Anxiety, working memory, gender, and math performance. Personality and Individual Differences, 37(3), 591-606. https://doi.org/10.1016/j.paid.2003.09.029

Morris, L. W., Davis, M. A., \& Hutchings, C. H. (1981). Cognitive and emotional components of anxiety: Literature review and a revised worry-Emotionality scale. Journal of Educational Psychology, 73(4), 541-555. https://doi.org/10.1037/0022-0663.73.4.541

Osborne, J. W. (2001). Testing stereotype threat: Does anxiety explain race and sex differences in achievement? Contemporary Educational Psychology, 26(3), 291-310. https://doi.org/10.1006/ceps.2000.1052

Park, D., Ramirez, G., \& Beilock, S. L. (2014). The role of expressive writing in math anxiety. Fournal of Experimental Psychology: Applied, 20(2), 103-111. https://doi.org/10.1037/xap0000013

Pekrun, R., Frenzel, A. C., Goetz, T., \& Perry, R. P. (2007). The control-value theory of achievement emotions: An integrative approach to emotions in education. In P. A. Schutz \& R. Pekrun (Eds.), Emotion in education (pp. 13-36). Amsterdam, The Netherlands: Academic Press. https://doi.org/10.1016/B978-012372545-5/50003-4

Ramirez, G., \& Beilock, S. L. (2011). Writing about testing worries boosts exam performance in the classroom. Science, 331(6014), 211-213. https://doi.org/10.1126/science.1199427

Richardson, F. C., \& Suinn, R. M. (1972). The mathematics anxiety rating scale: Psychometric data. fournal of Counseling Psychology, 19(6), 551-554. https://doi.org/10.1037/h0033456

Sarason, I. G. (1984). Stress, anxiety, and cognitive interference: Reactions to tests. fournal of Personality and Social Psychology, 46(4), 929-938. https://doi.org/10.1037/0022-3514.46.4.929 
Sarason, S. B., \& Mandler, G. (1952). Some correlates of test anxiety. Fournal of Abnormal and Social Psychology, 47(4), 810-817. https://doi.org/10.1037/h0060009

Schmader, T., \& Johns, M. (2003). Converging evidence that stereotype threat reduces working memory capacity. Fournal of Personality and Social Psychology, 85(3), 440-452. https://doi.org/10.1037/0022-3514.85.3.440

Tabachnick, B. G., \& Fidell, L. S. (2013). Using multivariate statistics (6th ed.). Harlow, United Kingdom: Pearson Education. van Ingen, D. J., Freiheit, S. R., \& Vye, C. S. (2009). From the lab to the clinic: Effectiveness of cognitive-behavioral treatments for anxiety disorders. Professional Psychology: Research and Practice, 40(1), 69-74. https://doi.org/10.1037/a0013318

Vukovic, R. K., Kieffer, M. J., Bailey, S. P., \& Harari, R. R. (2013). Mathematics anxiety in young children: Concurrent and longitudinal associations with mathematical performance. Contemporary Educational Psychology, 38(1), 1-10.

https://doi.org/10.1016/j.cedpsych.2012.09.001

Walter, H. (2018). The effect of expressive writing on second-grade math achievement and math anxiety (Doctoral dissertation, George Fox University, Newberg, OR, USA). Retrieved from https://digitalcommons.georgefox.edu/edd/106

Wegner, D. M., Schneider, D. J., Carter, S. R., \& White, T. L. (1987). Paradoxical effects of thought suppression. fournal of Personality and Social Psychology, 53(1), 5-13. https://doi.org/10.1037/0022-3514.53.1.5

Williams, J. E. (1996). Gender-related worry and emotionality test anxiety for high-achieving students. Psychology in the Schools, 33(2), 159-162. https://doi.org/10.1002/(SICI)1520-6807(199604)33:2<159::AID-PITS9>3.0.CO;2-M

Wood, J. (2006). Effect of anxiety reduction on children's school performance and social adjustment. Developmental Psychology, 42(2), 345-349. https://doi.org/10.1037/0012-1649.42.2.345

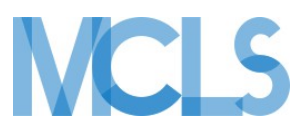

Journal of Numerical Cognition (JNC) is an official journal of the Mathematical Cognition and Learning Society (MCLS).
(P) leibniz-psychology.org

PsychOpen GOLD is a publishing service by Leibniz Institute for Psychology (ZPID), Germany. 